\title{
Detecting Safety Zone Drill Process Parameters for Uncoated HSS Twist Drill in Machining GFRP Composites by Integrating Wear Rate and Wear Transition Mapping
}

\author{
Sathish Rao Udupi ${ }^{1}$ and Lewlyn Lester Raj Rodrigues ${ }^{2}$ \\ ${ }^{1}$ Department of Mechanical and Manufacturing Engineering, Manipal Institute of Technology, Manipal University, \\ Manipal 576104, India \\ ${ }^{2}$ Department of Humanities and Management, Manipal Institute of Technology, Manipal University, Manipal 576104, India \\ Correspondence should be addressed to Sathish Rao Udupi; sathishraou@yahoo.com
}

Received 4 March 2016; Revised 18 May 2016; Accepted 13 June 2016

Academic Editor: Pradeep Lancy Menezes

Copyright (C) 2016 S. R. Udupi and L. Lester Raj Rodrigues. This is an open access article distributed under the Creative Commons Attribution License, which permits unrestricted use, distribution, and reproduction in any medium, provided the original work is properly cited.

\begin{abstract}
The previous research investigations informed that the tool wear of any machining operation could be minimized by controlling the machining factors such as speed, feed, geometry, and type of cutting tool. Hence the present research paper aims at controlling the process parameters to minimize the drill tool wear, during the machining of Glass Fiber Reinforced Polymer (GFRP) composites. Experiments were carried out to find the tool wear rate and a wear mechanism map of uncoated High Speed Steel (HSS) drill of $10 \mathrm{~mm}$ diameter was developed for the drilling of GFRP composite laminates. The surface micrograph images on the drill land surface displayed dominant wear mechanisms induced on HSS drill during machining of GFRP and they were found to be adhesive wear, adhesive and abrasive wear, abrasive wear, and diffusion and fatigue wear. A "safety wear zone" was identified on the wear mechanism map, where the minimum tool wear of the HSS drill occurs. From the safety zone boundaries, it was inferred that the drill spindle speed should be set between 1200 and $1590 \mathrm{rpm}$ and feed rate must be set within a range of $0.10-0.16 \mathrm{~mm} / \mathrm{rev}$ for GFRP work and HSS tool combination to enhance the service life of $10 \mathrm{~mm}$ HSS drills and to minimize the tool wear.
\end{abstract}

\section{Introduction}

Machining using the cutting tool is the collective process of friction and wear at the tool-work interface zone. During machining, the cutting tool undergoes tool wear that reduces the life of the cutting tool and reduces the productivity but increases the surface roughness of the machined work pieces. In recent days, polymer matrix composites have found wide range of applications starting from household appliances up to the extent of automobile and aircraft components. Drilling is one of the most essential machining operations used for polymer matrix composites in assembly operation using fasteners $[1,2]$. Because of the discovery of more effective and efficient automobile/aircraft components and their corresponding materials, along with the addition of modern CNC machines for machining, the manufacturer's prerequisite is to increase the life of cutting tools during the machining process in order to increase the machining efficiency and to lower the manufacturing/production cost [3]. However, the studies on the wear rates and wear mechanisms of cutting tools in drilling of polymer matrix composites are very limited and are still not enough to meet the industrial requirements of manufacturing and machining $[4,5]$. Therefore the wear rate map and wear transition/mechanism map pertaining to a specific cutting tool/work piece pair becomes prominent for selecting the appropriate machining parameters since the whole wear rate map and wear mechanism maps are plotted under various machining process conditions and machining parameters [6].

In the late 80s, Lim and Ashby constructed the first wear mechanism map in the tribology field $[7,8]$, which combined theoretical and practical works together. In the early 90 s, a wear mechanism map of aluminum alloys was constructed by $[9,10]$. After systematic studies on the wear process of cutting 


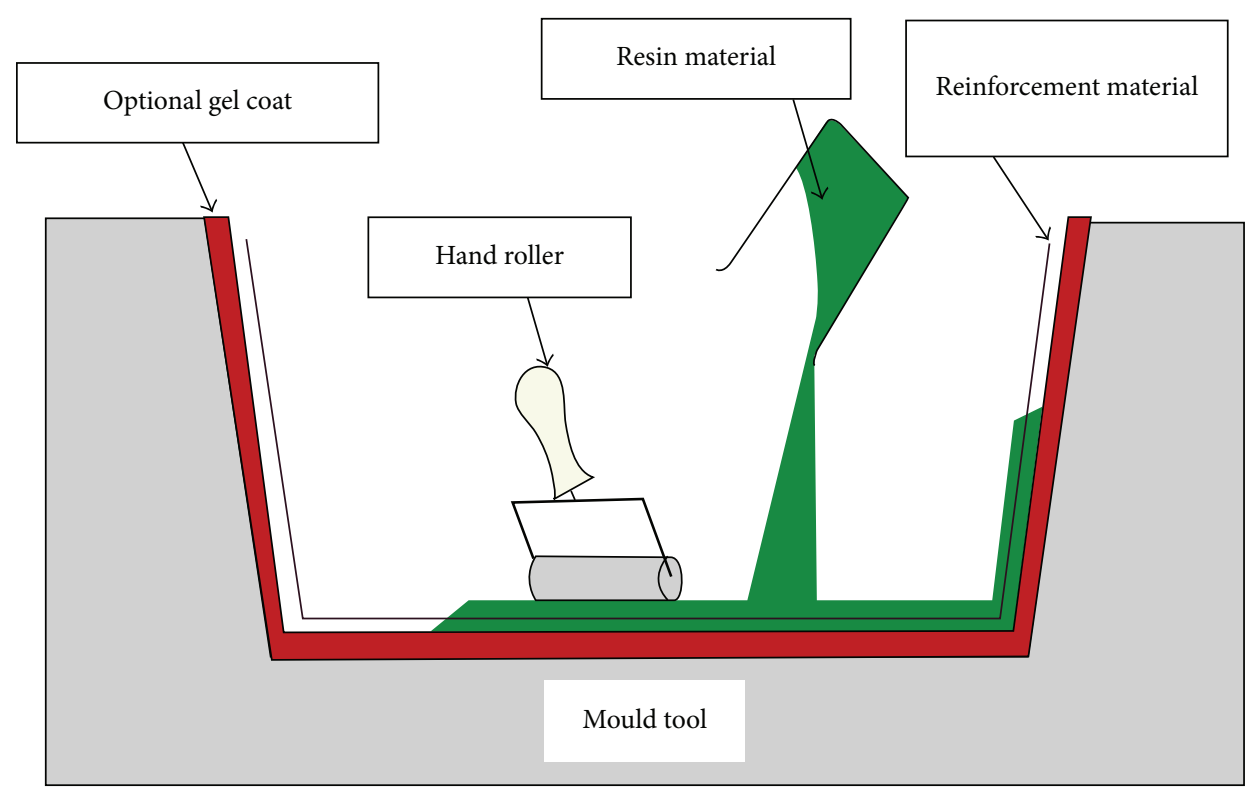

FIGURE 1: Hand lay-up process for fabricating composite materials.

tools, Lim and coworkers constructed few wear maps of tools cutting steels, which used feed rates and cutting speeds as two axes, respectively [11-13]. These maps explained the tribological characteristics of HSS tool while machining steels and relative wear mechanisms in different regions under dry running conditions. But it was predicted that it is possible to use the wear mechanism maps for other form of machining and also to predict the general trend of tool wear. It is also possible to identify some important regions on such maps such as the approximate location of the safety zone or the lower-wear regions [6].

As one more addition to this, in one of the earlier research works, the expression for wear rate in various regimes was examined critically. The important parameters that governed wear rate were identified and an approach to improve wear rate in each regime was suggested on the basis of identified parameters [14]. Recently wear mechanism maps were developed for high temperature applications for boron steel metals and these maps were also used for the study of wear behavior of boron steels under various loading conditions [15].

GFRP composites are being treated as one of the most widely used materials in automobile and aircraft industry due to their discrete advantages. Drilling is an important machining operation carried out on the GFRP composite material especially during the assembly based operations. Adding to this there is limited literature available on the wear behavior of cutting tools machining GFRP composites. So, in the present research work, an attempt was made to develop the wear mechanism map of drilled tools. The research work also aims at identifying the safety zone in which the wear rate of tools would be minimum. By operating the tools under safety zone process parameters, the tool performance can be improved, thus indirectly enhancing the productivity. The developed wear maps also describe the tribological features of
TABLE 1: GFRP composite specifications.

\begin{tabular}{lc}
\hline Matrix material & Isophthalic polyester resin \\
Fiber & S-glass fiber \\
Fiber diameter & 15 microns \\
Fabric type & Stitched mat type \\
Fiber orientation & Random \\
Fiber weight fraction & $33 \%$ \\
Material density & $1.6 \mathrm{~g} / \mathrm{mm}^{3}$ \\
Laminate thickness & $10 \mathrm{~mm}$ \\
\hline
\end{tabular}

HSS tool drilling GFRP composite and relative wear mechanisms in different regions under dry machining conditions. Thus, in the later stage, these developed wear maps could be treated as good references for choosing suitable processing parameters for uncoated HSS tools drilling of GFRP composites.

\section{Materials and Methods}

2.1. GFRP Material Fabrication. Approximately $2 \mathrm{kgs}$. of isophthalic polyester resin along with the hardener (polyether ether ketone) was mixed with $1 \mathrm{~kg}$ of structural glass reinforcement with mat fabric (fiber weight fraction (FWF) = $33 \%$ ). The other properties of the GFRP composite are listed in Table 1. Laminate samples with dimension of $600 \times 600 \times$ $10 \mathrm{~mm}$ were fabricated using hand lay-up process (Figure 1). The laminate was cured under atmospheric temperature and pressure conditions. The GFRP composite laminate after the fabrication is shown in Figure 2.

The wear mechanism map of uncoated HSS drill tools machining GFRP composite laminates is constructed by wear 


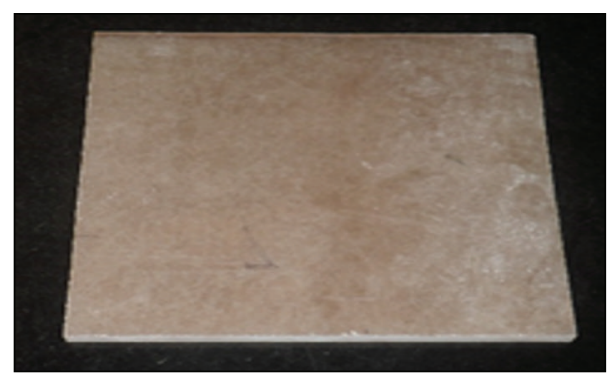

FIGURE 2: GFRP composite laminate fabricated by Hand lay-up process.

TABLE 2: Drill tool dimension specifications.

\begin{tabular}{lc}
\hline Tool material & High speed steel \\
Tool diameter & $10 \mathrm{~mm}$ \\
No. of Flutes & 2 \\
Point angle & $118^{\circ}$ \\
Helix angle & $30^{\circ}$ \\
Flute length & $87 \mathrm{~mm}$ \\
Shank type & Cylindrical \\
\hline
\end{tabular}

data collection. The wear data is collected through experimental work by considering drilling process parameters at different levels. The GFRP work piece material laminate thickness is retained constant at $10 \mathrm{~mm}$. Bosch manufactured uncoated HSS drill tool of $10 \mathrm{~mm}$ (refer to Table 2 for specifications) was used for drilling in dry run condition.

A Computer Numerical Controlled (CNC) Vertical Machining Center (VMC) was used to perform the drilling operation (Figure 3) to have more accurate and reliable data collection for constructing the wear maps. During machining, 80 holes of $10 \mathrm{~mm}$ diameter were drilled on the composite laminate using uncoated HSS twist drill (Figure 4), as per the drill hole spacing specifications and standards for fasteners. The spindle speed varied from $1200 \mathrm{rpm}(22.62 \mathrm{~m} / \mathrm{min})$ to $1800 \mathrm{rpm}(33.93 \mathrm{~m} / \mathrm{min})$ while the feed rate is varied from $0.1 \mathrm{~mm} / \mathrm{rev}$ to $0.3 \mathrm{~mm} / \mathrm{rev}$ as shown in Table 3 .

Before and after drilling the holes, the HSS drills were cleaned with acetone and $\mathrm{NaOH}$ solution to remove the impurities. A fresh HSS drill was used for each experimental run and two replications of each run were carried out for wear data collection. In the present research, the tool wear rate was measured by applying the weight difference method. The average of weight difference of two replications of each experimental run is calculated and considered for analysis. The wear data along with the study of micrograph images are used for plotting the wear maps. The value of the wear rate measured was normalised using the following formula [16]:

$$
\text { Normalised wear rate }=W_{n}=\frac{W}{A_{n}}
$$

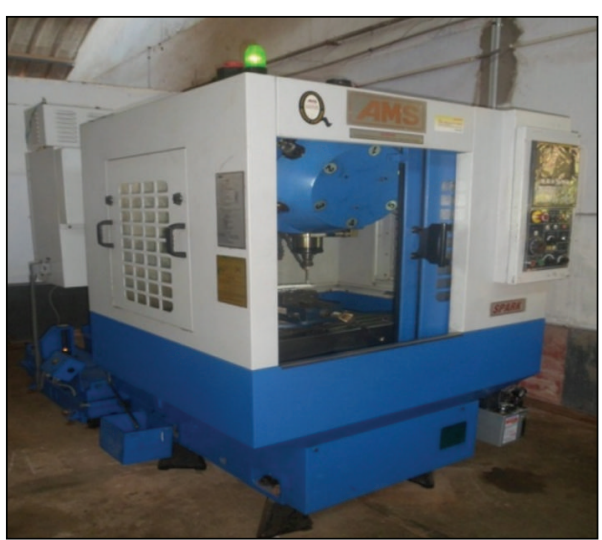

Figure 3: CNC Vertical Machining Center.

where $W$ is wear rate and $A_{n}$ is Nominal contact area:

$$
\begin{aligned}
W & =\text { wear rate } \\
& =\frac{\text { Weight lost in time }}{\text { Density }}\left(\mathrm{mm}^{3} \mathrm{~min}^{-1}\right), \\
\text { Weight loss } & =\frac{\text { Weight }_{\text {before }}-\text { Weight }_{\mathrm{after}}}{\text { Time }}(\mathrm{g} / \mathrm{min}) .
\end{aligned}
$$

The drill process parameters chosen and the normalised and the dimensionless wear rate data are shown in Table 3.

\subsection{Plotting Wear Rate Map of Uncoated HSS Twist Drill Tools} of $10 \mathrm{~mm}$ Diameter. After machining, the drills were placed under Trinocular Inverted Metallurgical Microscope to study the micrograph analysis. The micrograph images of the chisel edge, drill land, and flank surfaces were captured with a magnification factor of 500x to identify different wear mechanisms during drilling operation. An Inverted Trinocular Metallurgical Microscope was used for micrograph analysis of worn tool surface, as shown in Figure 5.

In the present work, the wear data and the wear rate/transition/mechanism map of $10 \mathrm{~mm}$ HSS drill while machining the GFRP composite are shown below.

2.3. Methodology of Wear Mapping. The following the steps explain the steps involved in the construction of wear rate/transition/mechanism maps in the present research work.

(1) For the pair of materials considered in this research work, that is, Glass Fiber Reinforced Polymer (GFRP) composite and HSS drill bits, their contact mode (unidirectional through hole drilling), their contact geometry (surface contact), the working environment condition in which the pair of materials are to interact (CNC drilling), and lubrication condition (dry run) is decided before starting the experiment.

(2) Experimental wear data was gathered from the inhouse drilling experiments carried out on the CNC Vertical Machining Center. Mathematical models 


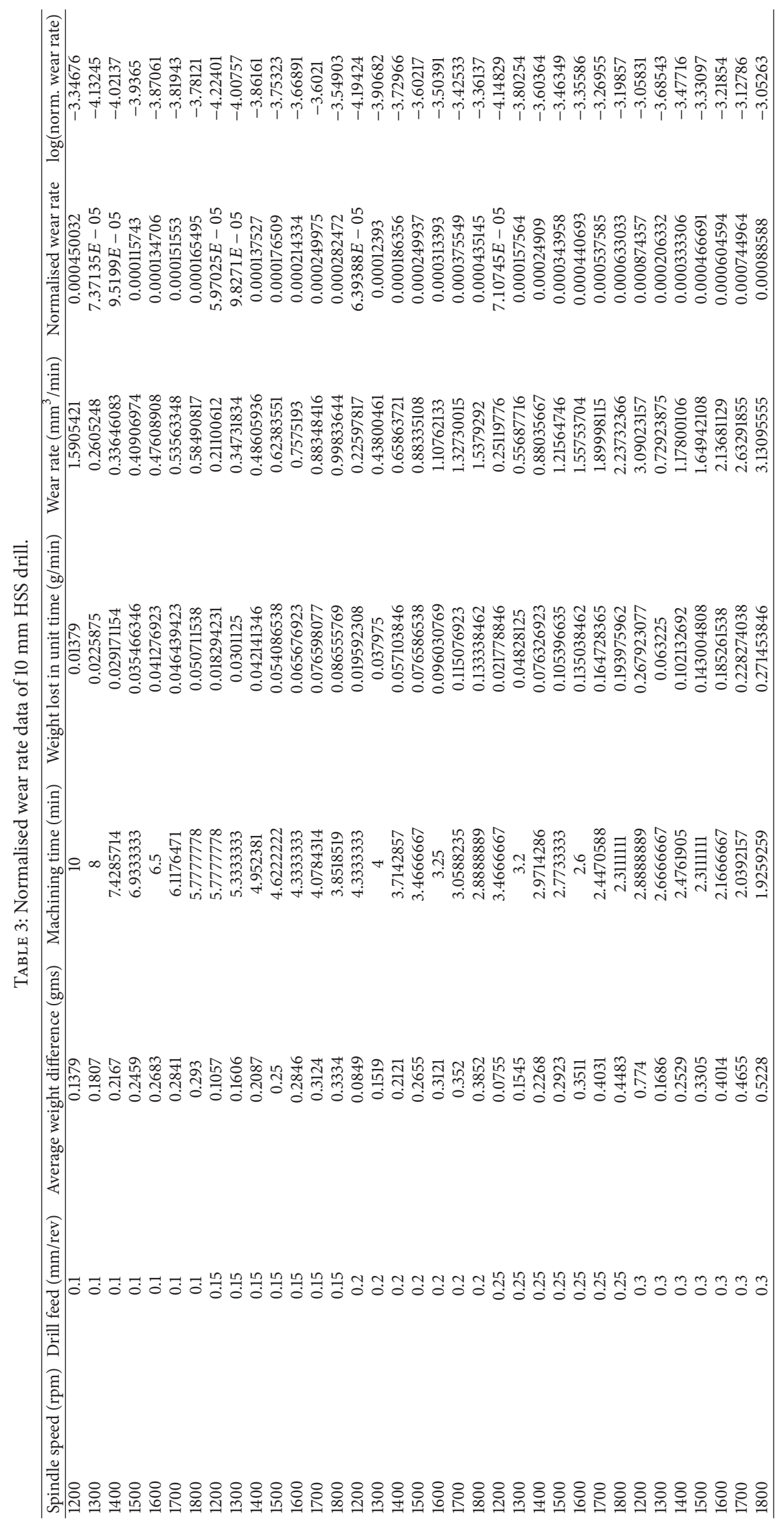




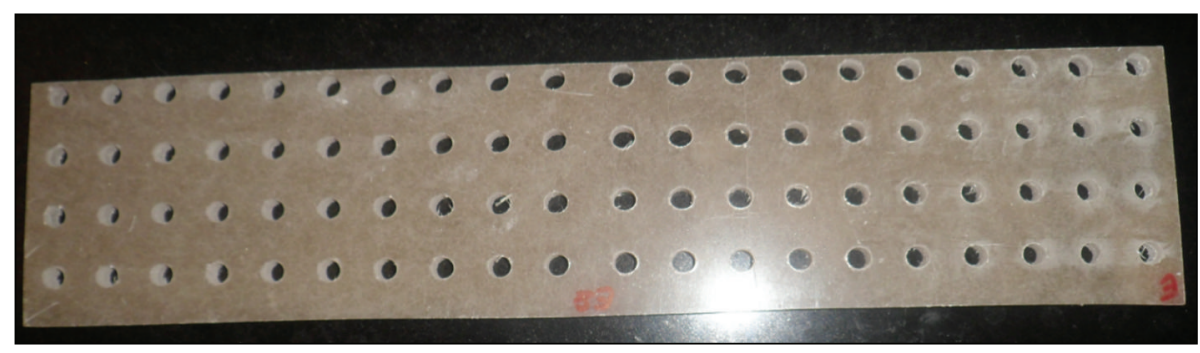

FIGURE 4: GFRP composite with holes drilled as per design standards.

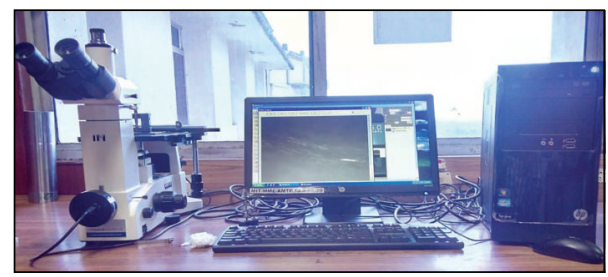

FIgURE 5: Trinocular Inverted Metallurgical Microscope.

describing wear behavior of this pair should be gathered through the literature review.

(3) The process parameters to be used as the two axes of the wear map and also their range to be included on the wear maps are decided.

(4) According to the mode and mechanism of wear, the wear data are grouped. The wear rate/wear transition/wear mechanism data, appropriately classified, are then plotted on the two-dimensional axes defining the map. Each mechanism is then separated using boundaries and the approximate locations of the contours of constant wear rate. At this stage, the wear map is sufficiently informative showing different wear mechanisms on the wear rate map.

(5) The final step is to identify the "safety zone" or "safe working region" "low wear zone" where the overall/ total drill tool wear is going to be minimum. This zone gives the optimum range of process parameters that could minimize the tool wear, indirectly enhancing the operational performance and life of the drill tool and ending with increased productivity.

For the present research work, the spindle speed and the feed rate were chosen as two axes required for constructing the two-dimensional wear map of HSS tools drilling GFRP composites. The wear rate maps were drawn by normalising the wear rate values against spindle speed and feed rate. Wear maps were built by taking spindle speed (rpm) as abscissa and the feed rate $(\mathrm{mm} / \mathrm{rev})$ as the ordinate.

\section{Results and Discussion}

3.1. Construction of Wear Maps. Figure 6 shows the wear rate map of $10 \mathrm{~mm}$ drill machining GFRP composite. The regions in the diagram were delineated where similar wear

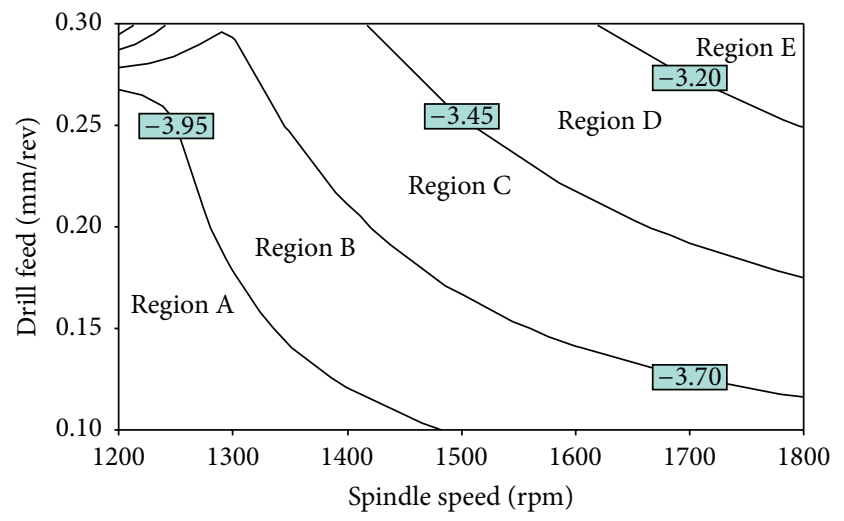

FIgURE 6: Wear rate map of $10 \mathrm{~mm}$ HSS drill drilling GFRP composite laminate.

rates are obtained and the boundaries are drawn whenever a significant change in the wear rate is observed. In this diagram, five such regions were identified and were separated by boundaries with a step interval of 0.25 based on the change of wear rate and the micrograph analysis of the drill surfaces taken from Inverted Trinocular Metallurgical Microscope under a magnification of 500x. The boundaries are shown with a continuous line in the map. The values of step interval include the following: -4.20 to -3.95 (region A), -3.95 to -3.70 (region $\mathrm{B}$ ), -3.70 to -3.45 (region $\mathrm{C}$ ), -3.45 to -3.2 (region $\mathrm{D}$ ), and -3.2 to -2.95 (region $\mathrm{E}$ ).

Under the operating conditions in the region A, a built-up edge (BUE) was observed beside the cutting edge of the drill (Figure 7). Due to the protective effect of the built-up edge on tool wear, the wear rate was found to be negligible in this region. Thus the wear mechanism of region A was reflected as adhesive wear [6]. It was also observed that there is a small lump of metal adhered on the boundary of the cutting edge and it is the built-up edge. This acts as a virtual cutting edge, to drill the GFRP composite and hence its existence reduces the tool wear. In addition to this, the formed built-up edge makes the chip breaking easy. Figure 7 also shows the accumulation and spreading of GFRP composite material on the land surface thus representing the occurrence of adhesive wear. So, region A shows the existence of built-up edge and the adhesive wear as well.

The microstructure of the worn surface of a drill tool under a cutting speed of $1400 \mathrm{rpm}$ and a feed rate of 

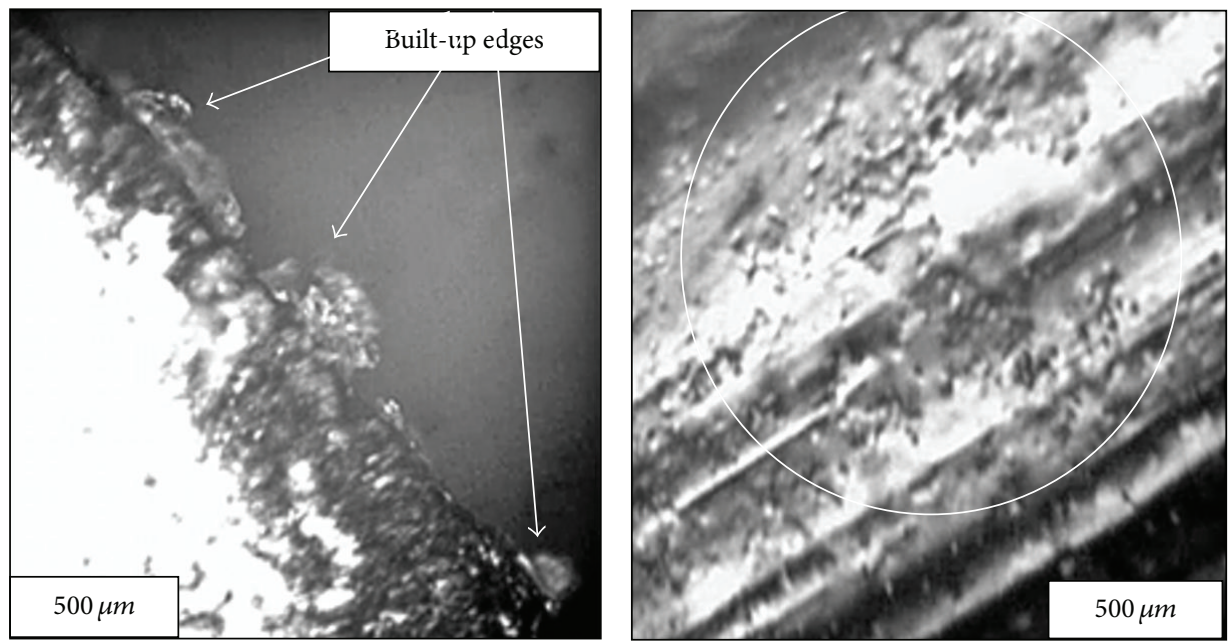

FIGURE 7: Worn land surface of the $10 \mathrm{~mm}$ HSS drill under a feed rate of $0.15 \mathrm{~mm} / \mathrm{rev}$ and at a spindle speed of $1300 \mathrm{rev} / \mathrm{min}$.

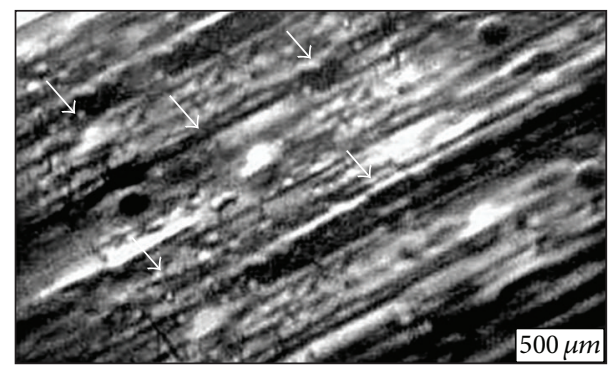

FIgURE 8: Worn land surface of the $10 \mathrm{~mm}$ HSS drill under a feed rate of $0.20 \mathrm{~mm} / \mathrm{rev}$ and at a spindle speed of $1400 \mathrm{rev} / \mathrm{min}$.

$0.20 \mathrm{~mm} / \mathrm{rev}$ (i.e., region B) is shown in Figure 8. The magnified image of the small area of land surface displays a surface with parallel plow ridges and adhered small mass of GFRP material on the ridges (shown by arrows) at many locations. Region B shows the adhesive wear mechanism. From the micrograph image of the drilled surface (discussed in the previous section) it could be seen that the particle dislodged from the cutting tool's land is adhered on to the hole surface, further confirming adhesive wear mechanism in this region.

The microscope image of the worn flank surface (Figure 9) of a drilled tool is captured under a cutting speed of $1500 \mathrm{rpm}$; a feed rate of $0.25 \mathrm{~mm} / \mathrm{rev}$ is shown. The worn flank surface reveals deep groove plowing. The image displays deeper ruptures and cracks (shown by arrows) on the ridges of the land surface of the drill. This could be due to the marginal increase in the cutting speed and feed rate at this region. Abrasive wear is the major wear mechanism in region C. The increase in the thermal flux at the tool-work interface dissociates the matrix/fiber bonding. The debonded hard and brittle glass fibers rub and abrade the tool surface thus indicating the presence of abrasive wear in region $\mathrm{C}$.

The microstructure of the worn flank surface of the drilled tool under a cutting speed of $1700 \mathrm{rpm}$ and a feed rate of $0.25 \mathrm{~mm} / \mathrm{rev}$ is shown in Figure 10. Micrograph image shows

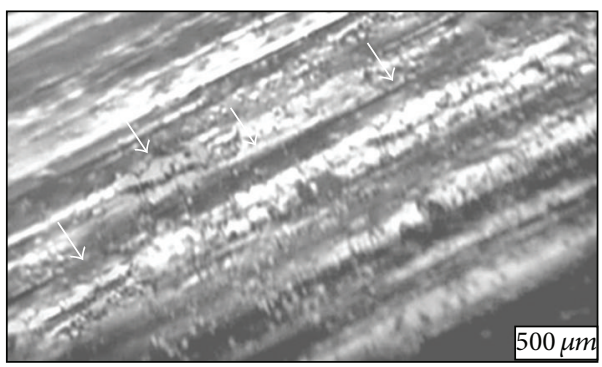

FIGURE 9: Worn land surface of the $10 \mathrm{~mm}$ HSS drill under a feed rate of $0.25 \mathrm{~mm} / \mathrm{rev}$ and at a spindle speed of $1500 \mathrm{rev} / \mathrm{min}$.

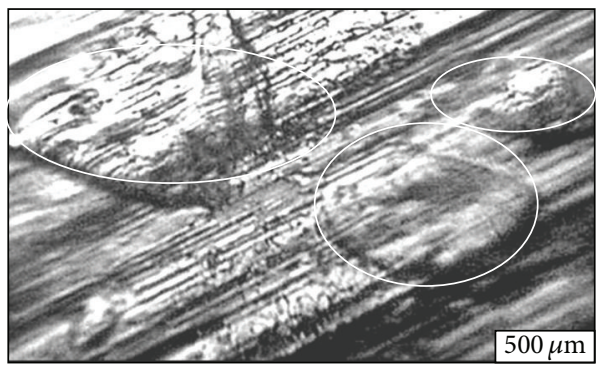

FIGURE 10: Worn land surface of the $10 \mathrm{~mm}$ HSS drill under a feed rate of $0.25 \mathrm{~mm} / \mathrm{rev}$ and at a spindle speed of $1700 \mathrm{rev} / \mathrm{min}$.

plastic deformation of the worn surface with cracks and substantial quantity of debris on it. The temperature generated at the tool-work interface with the increasing cutting speeds and feed rates resulted in speedy wear of drilling tools. Thus in region $\mathrm{D}$ (Figure 10), the wear mechanism is controlled by temperature. Also, the material accumulation in the form of lumps (shown by circles in Figure 10) indicates the occurrence of diffusion on the drill land surface because of elevated temperature. Therefore, in this region, the drill tool wear increases rapidly and drilling operation is not recommended. 

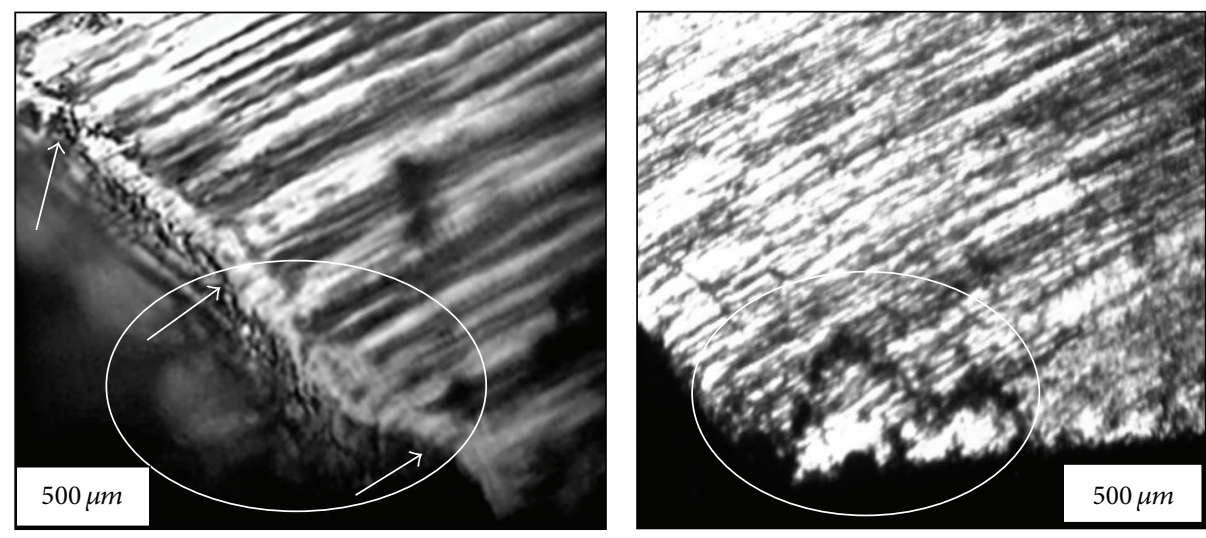

FIGURE 11: Worn land surface of the $10 \mathrm{~mm}$ HSS drill under a feed rate of $0.30 \mathrm{~mm} / \mathrm{rev}$ and at a spindle speed of $1800 \mathrm{rev} / \mathrm{min}$.

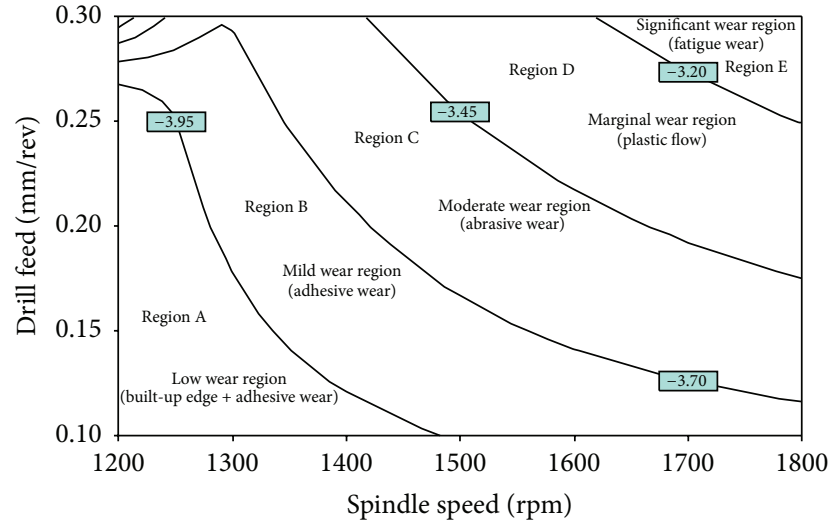

FIGURE 12: Wear mechanism/transition map of $10 \mathrm{~mm}$ HSS drill in GFRP composite machining.

Figure 11 shows the micrograph image of the worn surface of cutting tools at a feed rate of $0.3 \mathrm{~mm} / \mathrm{rev}$ and a cutting speed of $1800 \mathrm{rev} / \mathrm{min}$, that is, region E. The worn surface in this region is composed of the rough and damaged waves of cutting edge, nonuniform land surface with small voids, and transferred material from the work piece. The edges of the land are damaged due to fatigue fracture, which occurs due to the increased applied load on the cutting edge. The load on the cutting edge increases due to increased level of process parameters and due to the thermal effects occurring at the tool-work interface as well [11]. The temperature developed at the interface is enough to create thermal impact on the cutting edge. This will lead to damaged/softened/deformed cutting edge as shown in Figure 11 (by arrows). Scaling of the surface is seen near the flank edge of the drill (shown by the ellipse). In this region, tool wear increases swiftly. Therefore, the drilling operations must be avoided.

Based on the above micrograph observations (Figures 7 to 11), the wear mechanism map for $10 \mathrm{~mm}$ HSS drill tool during dry drilling of GFRP composite is developed and is shown in Figure 6. The wear mechanisms include built-up edge + adhesive wear, adhesive and abrasive wear, abrasive wear, plastic flow, and fatigue/thermal wear (Figure 12). These mechanisms inferred that regions $\mathrm{A}, \mathrm{B}$, and $\mathrm{C}$ are the plastic deformation controlled regimes with varying wear rates from -4.2 to -3.45 . The micrograph findings showed that the wear mechanisms under these regions could be due to the builtup edge formation, adhesion, and adhesion and abrasion of the GFRP material constituents on the drill land and flank surface. The micrograph findings also indicated that regions $\mathrm{D}$ and $\mathrm{E}$ are thermally sensitive with the wear rates of -3.45 and above. The micrograph analysis indicated that the wear mechanisms in these regimes could be fatigue wear/plastic flow and machining in these regimes must be avoided.

In Figure 5, out of the five regions identified and differentiated based on the wear rate, region $\mathrm{A}$ has the lowest wear rate $(-3.95$ to -4.20$)$ compared to other regions which can be the "safety zone" for $10 \mathrm{~mm}$ drill. This "safety zone" gives the optimal machining parameters with an acceptable wear rate. It was inferred that the life of the drill tool can be enhanced if the drilling parameters were made to operate within the range, of the "safety zone." The operational parameters of the "safety zone" for $10 \mathrm{~mm}$ HSS drill are as follows:

Drill spindle speed: $1200 \sim 1480 \mathrm{rpm}$.

Drill feed rate: $0.10 \sim 0.27 \mathrm{~mm} / \mathrm{rev}$.

\section{Conclusions}

(1) The wear rate maps were clearly delineated into low wear region, mild wear region, moderate wear region, marginal wear region, and significant wear region. The regions in the diagram are delineated where similar wear rates were obtained and the boundaries are plotted according to the observed change in the wear rate.

(2) Micrograph observations showed adhesive pits, voids, adhesion of polyester matrix, minor cracks, deep parallel ridges, and plowing marks on the land/flank surface of the HSS drill.

(3) Five types of wear mechanisms were identified in the present work based on the micrograph observations of the worn surfaces of uncoated HSS tools, during the drilling of GFRP composites. 
(4) The main wear mechanisms in the map include builtup edge, adhesive wear, adhesive and abrasive wear, abrasive wear, plastic flow, and fatigue/thermal wear.

(5) In order to improve the operational performance of the drill tool for the specified GFRP material, tool material, and machining conditions, the process parameters can be set corresponding to "safety cutting zone" or "mild wear region" so as to have minimum tool wear. The drill parameters that can be set for this are as follows:

spindle speed: in a range of 1200 to $1590 \mathrm{rpm}$;

drill feed rate: in a range of 0.10 to $0.16 \mathrm{~mm} / \mathrm{rev}$.

\section{Competing Interests}

The authors declare that they have no competing interests.

\section{References}

[1] S. Gowri and F. H. Samuel, "Effect of alloying elements on the solidification characteristics and microstructure of $\mathrm{Al}-\mathrm{Si}-\mathrm{Cu}-$ Mg-Fe 380 alloy," Metallurgical and Materials Transactions A, vol. 25, no. 2, pp. 437-448, 1994.

[2] H. R. Leep, E. D. Halbleib, and Z. Jiang, "Surface quality of holes drilled into aluminium 390," International Journal of Production Research, vol. 29, no. 2, pp. 391-400, 1991.

[3] H. R. Leep and T. W. Eldridge, "Effects of cutting conditions on drilling of aluminum 380," Journal of Materials Engineering and Performance, vol. 1, no. 6, pp. 797-800, 1992.

[4] M. Zhang, H. Zhou, T. Liang, and Y. B. Liu, "Intermetallic compounds in die casting aluminum alloys," Special Casting or Nonferrous Alloys, vol. 1, pp. 117-119, 1999.

[5] M. Z. Zhang, Y. B. Liu, and H. Zhou, "Wear mechanism maps of uncoated HSS tools drilling die-cast aluminum alloy," Tribology International, vol. 34, no. 11, pp. 727-731, 2001.

[6] J. Wang, Y. B. Liu, J. An, and L. M. Wang, "Wear mechanism map of uncoated HSS tools during drilling die-cast magnesium alloy," Wear, vol. 265, no. 5-6, pp. 685-691, 2008.

[7] S. C. Lim and M. F. Ashby, "Wear-mechanism maps," Acta Metallurgica, vol. 35, no. 1, pp. 1-24, 1987.

[8] M. F. Ashby and S. C. Lim, "Wear-mechanism maps," Scripta Metallurgica et Materiala, vol. 24, no. 5, pp. 805-810, 1990.

[9] Z. Cao, LuLu, D. Sun, and Y. B. Liu, "Methodology and development of wear maps research," Tribology International, vol. 17, pp. 187-192, 1997.

[10] Y. B. Liu, R. Asthana, and P. A. Rohatgi, "A map for wear mechanisms in aluminium alloys," Journal of Materials Science, vol. 26, no. 1, pp. 99-102, 1991.

[11] S. C. Lim, S. H. Lee, Y. B. Liu, and K. H. W. Seah, "Wear maps for uncoated high-speed steel cutting tools," Wear, vol. 170, no. 1, pp. 137-144, 1993.

[12] S. H. Lee, S. C. Lim, Y. B. Liu, and K. H. W. Seah, "Wear mechanism of cutting tools: uncoated high-speed-steel cutting tools," Journal of Institute of Engineers, vol. 34, pp. 29-34, 1994.

[13] S. H. Lee, S. C. Lim, Y. B. Liu, and K. H. W. Seah, "Wear mechanism of cutting tools: uncoated carbide cutting tools," Journal of Institute of Engineers, vol. 34, pp. 35-40, 1994.
[14] M. Roy, "Use of wear mechanism map to engineer surfaces for enhanced wear resistance," Transactions of the Indian Institute of Metals, vol. 62, no. 3, pp. 197-208, 2009.

[15] S. Hernandez, Tribodays 2013, Luleå University of Technology, Luleå, Sweden, 2013.

[16] V. Srinivasan, K. V. Maheshkumar, R. Karthikeyan, and K. Palanikumar, "Application of probablistic neural network for the development of wear mechanism map for glass fiber reinforced plastics," Journal of Reinforced Plastics and Composites, vol. 26, no. 18, pp. 1893-1906, 2007. 

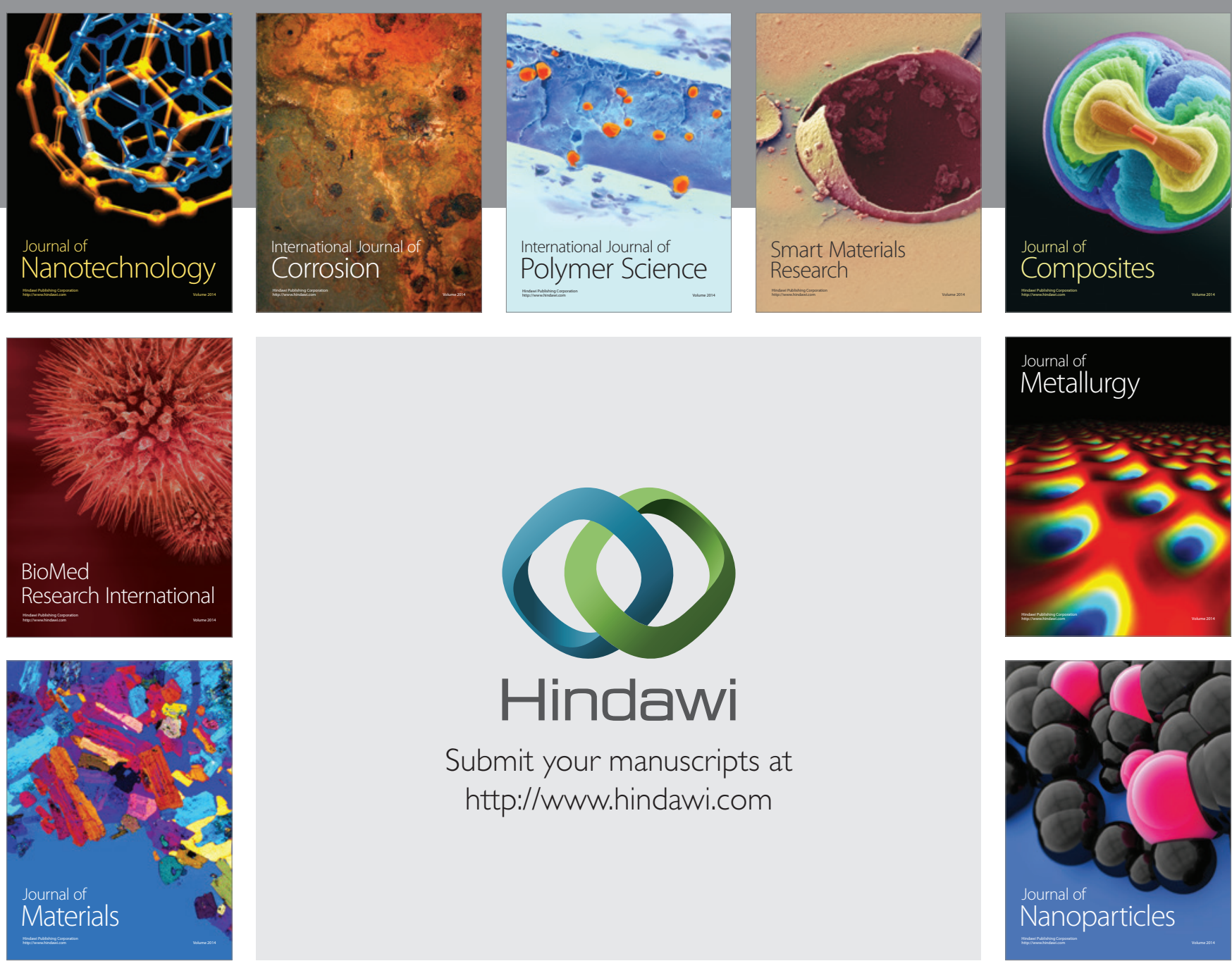

\section{Hindawi}

Submit your manuscripts at

http://www.hindawi.com

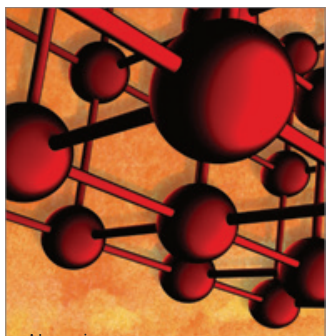

Materials Science and Engineering
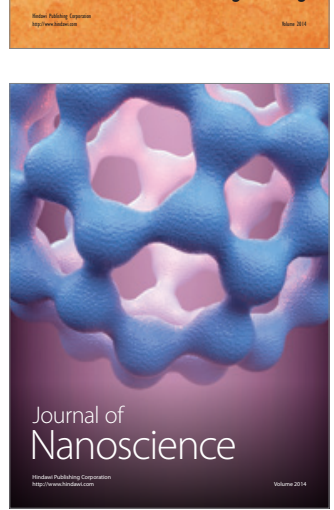
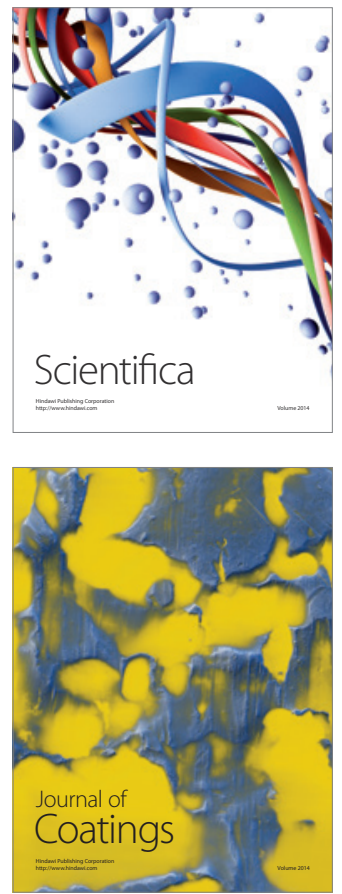
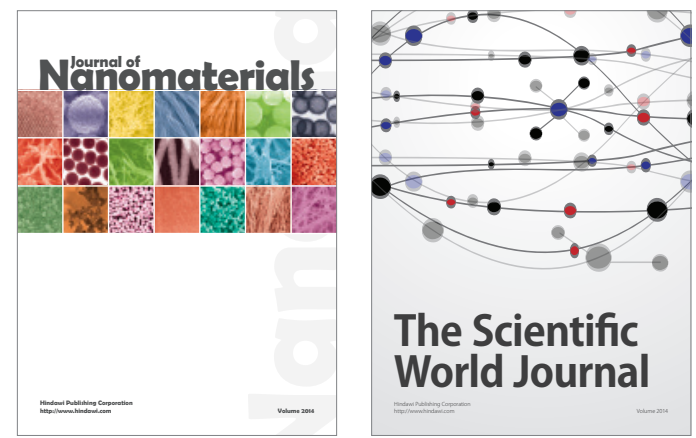

The Scientific World Journal
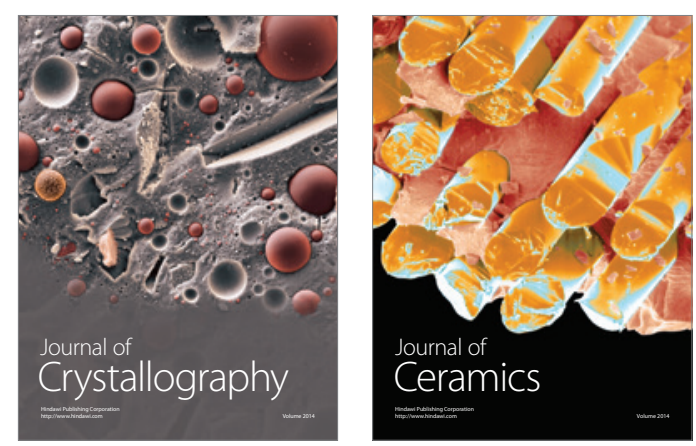
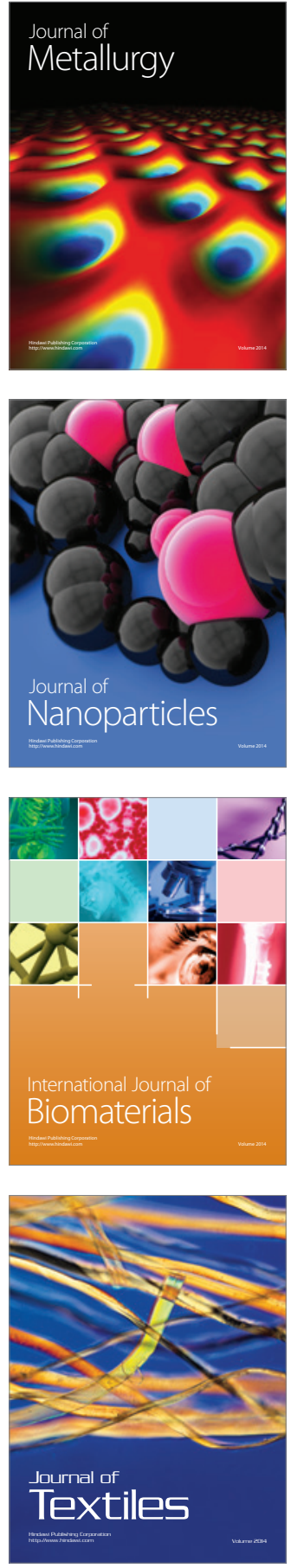